\title{
VEGF over-expression in skeletal muscle induces angiogenesis by intussusception rather than sprouting
}

\author{
Roberto Gianni-Barrera · Marianna Trani • \\ Christian Fontanellaz • Michael Heberer • \\ Valentin Djonov • Ruslan Hlushchuk • Andrea Banfi
}

Received: 10 April 2012/Accepted: 28 August 2012/Published online: 9 September 2012

(C) Springer Science+Business Media B.V. 2012

\begin{abstract}
Therapeutic over-expression of vascular endothelial growth factor (VEGF) can be used to treat ischemic conditions. However, VEGF can induce either normal or aberrant angiogenesis depending on its dose in the microenvironment around each producing cell in vivo, which limits its clinical usefulness. The goal herein was to determine the cellular mechanisms by which physiologic and aberrant vessels are induced by over-expression of different VEGF doses in adult skeletal muscle. We took advantage of a well-characterized cell-based platform for controlled gene expression in skeletal muscle. Clonal populations of retrovirally transduced myoblasts were implanted in limb muscles of immunodeficient mice to homogeneously over-express two specific $\mathrm{VEGF}_{164}$ levels, previously shown to induce physiologic and therapeutic or aberrant angiogenesis, respectively. Three independent and complementary methods (confocal microscopy, vascular casting and 3D-reconstruction of serial semi-thin sections) showed that, at both
\end{abstract}

Electronic supplementary material The online version of this article (doi:10.1007/s10456-012-9304-y) contains supplementary material, which is available to authorized users.

R. Gianni-Barrera · M. Trani · M. Heberer · A. Banfi $(\bowtie)$

Cell and Gene Therapy, Department of Biomedicine and

Department of Surgery, Basel University Hospital,

ICFS 407, Hebelstrasse 20, 4031 Basel, Switzerland

e-mail: abanfi@uhbs.ch

C. Fontanellaz · V. Djonov · R. Hlushchuk $(\bowtie)$

Institute of Anatomy, University of Bern, Baltzerstrasse 2,

3000 Bern, Switzerland

e-mail: ruslan.hlushchuk@ana.unibe.ch
VEGF doses, angiogenesis took place without sprouting, but rather by intussusception, or vascular splitting. VEGFinduced endothelial proliferation without tip-cell formation caused an initial homogeneous enlargement of pre-existing microvessels, followed by the formation of intravascular transluminal pillars, hallmarks of intussusception. This was associated with increased flow and shear stress, which are potent triggers of intussusception. A similar process of enlargement without sprouting, followed by intussusception, was also induced by VEGF over-expression through a clinically relevant adenoviral gene therapy vector, without the use of transduced cells. Our findings indicate that VEGF over-expression, at doses that have been shown to induce functional benefit, induces vascular growth in skeletal muscle by intussusception rather than sprouting.

Keywords VEGF · Angiogenesis · Intussusception · Skeletal muscle · Gene therapy

$\begin{array}{ll}\text { Abbreviations } \\ \text { VEGF } & \text { Vascular endothelial growth factor } \\ \text { NG2 } & \text { Nerve/glial antigen-2 } \\ \text { SMA } & \text { Smooth muscle actin } \\ \text { KLF-2 } & \text { Krüppel-like factor-2 } \\ \text { eNOS } & \text { Endothelial nitric oxide synthase } \\ \text { IRES } & \text { Internal rybosomal entry site } \\ \text { FACS } & \text { Fluorescence activated cell sorter } \\ \text { SCID } & \text { Severe combined immunodeficiency }\end{array}$

\section{Introduction}

Angiogenesis, i.e. the growth of new blood vessels from pre-existing ones, is a process that can be targeted to 
restore blood supply to ischemic tissues. Vascular endothelial growth factor (VEGF) is the master regulator of vascular growth both in development and disease and, upon expression as a single factor, is capable of initiating the cascade of events leading from endothelial activation to the generation of new functional and stable vascular networks [1]. However, we previously found that VEGF can induce the growth of either normal capillary networks or aberrant angioma-like structures depending on its expression level in the microenvironment around each producing cell in vivo and not on the total dose delivered, since it remains tightly bound to the extracellular matrix $[2,3]$. The need to strictly control VEGF dose distribution in vivo poses a major challenge to its therapeutic exploitation [4-6]. Understanding how normal or aberrant vessels are formed after expression of specific VEGF doses is crucial to design new rational therapeutic strategies. Our current comprehension of the initiation of vessel growth is mostly based on powerful genetic models of developmental angiogenesis, in which new vessels sprout to invade and vascularize non-perfused tissue, such as the newborn mouse retina [7]. However, in skeletal and cardiac muscle, which are the target tissues of ischemia treatments, extensive pre-existing vascular networks are present, from which new vessels are induced therapeutically by over-expression of factors well above endogenous levels.

Skeletal muscle angiogenesis has been shown to take place by sprouting after up-regulation of endogenous VEGF expression, for example during the adaptation to exercise training $[8,9]$ or in the reparative response to ischemia [10]. However, several studies found that vascular growth in skeletal muscle can also take place through another complementary mechanism called intussusception, or splitting angiogenesis. Characteristic for this process is the formation of transluminal pillars, which fuse progressively together and split the affected vascular segment [11]. Key stimuli to initiate pillar formation have been found to be increased blood flow and shear stress [12-14]. Initial pillar formation can occur either through a zone of contact between the endothelial cells of opposite capillary walls, with subsequent reorganization of the endothelial junctions and invasion of the pillar core by myofibroblasts $[15,16]$, or through the extension and fusion of intraluminal protrusions made exclusively of endothelial cells [17]. It is not yet clear whether these two processes take place in different kinds of vessels, but eventually both lead to the generation of new vascular segments by longitudinal splitting rather than by ab-luminal sprouting.

Therefore, we took advantage of a unique and wellcharacterized cell-based platform for controlled gene expression in skeletal muscle $[2,3,18]$ to investigate the cellular mechanisms by which specific VEGF doses across the therapeutic to toxic range induce normal or aberrant angiogenesis in clinically relevant conditions.

\section{Methods}

Cell culture

Primary myoblasts isolated from C57BL/6 mice and already transduced with a retrovirus expressing the $\beta$-gal marker gene were further infected at high efficiency, as previously described [19], with a retroviral construct carrying the cDNA for murine $\mathrm{VEGF}_{164}$ linked through an Internal Ribosomal Entry Sequence (IRES) to a truncated version of murine CD8a (trCD8a) [18]. Control CD8 cells expressed only trCD8a and no VEGF. Early-passage myoblast clones were isolated using a FACS Vantage SE cell sorter (Becton-Dickinson, Basel, Switzerland) and single cell isolation was confirmed visually. All myoblast populations were cultured in $5 \% \mathrm{CO}_{2}$ on collagen-coated dishes, with a growth medium consisting of $40 \%$ F10, $40 \%$ DMEM (Sigma-Aldrich Chemie GmbH, Steinheim, Germany) and $20 \%$ fetal bovine serum (HyClone, Logan, UT), supplemented with $2.5 \mathrm{ng} / \mathrm{ml} \mathrm{FGF-2} \mathrm{(R \& D} \mathrm{Systems,}$ Abingdon, UK), as described [20].

\section{VEGF $_{164}$ ELISA measurements}

The production of $\mathrm{VEGF}_{164}$ in cell culture supernatants was quantified using a Quantikine mouse VEGF Immunoassay ELISA kit (R\&D Systems, Abingdon, UK). One $\mathrm{ml}$ of medium was harvested from myoblasts in one $60 \mathrm{~mm}$ dish, following a 4-h incubation, filtered and analyzed in duplicate. Results were normalized for the number of cells in the dish and time of exposure to medium. Four dishes of cells were assayed per cell type $(n=4)$.

Myoblast implantation into mice

Cells were implanted into 5-10 week-old immunodeficient SCID CB.17 mice (Charles River Laboratories, Sulzfeld, Germany) in order to avoid an immunological response to $\beta$-galactosidase-expressing myoblasts. Animals were treated in accordance with Swiss Federal guidelines for animal welfare and the study protocol was approved by the Veterinary Office of the Canton Basel-Stadt (Basel, Switzerland). Myoblasts were dissociated in trypsin and resuspended at a concentration of $10^{8}$ cells $/ \mathrm{ml}$ in sterile PBS with $0.5 \%$ BSA. $1 \times 10^{6}$ cells in $10 \mu \mathrm{l}$ were implanted into the posterior auricular muscle, midway up the dorsal aspect of the external ear, or into the tibialis anterior (TA) and gastrocnemius (GC) muscles of the leg, 
using a syringe with a $29 \frac{1}{2} \mathrm{G}$ needle, as previously described [2].

Recombinant adenovirus production

Recombinant adenoviruses expressing either mouse VEGF $_{164}$ linked to truncated CD8a in a bicistronic cassette, or only CD8a as control, were produced using the Adeno$\mathrm{X}^{\mathrm{TM}}$ Expression System (Clontech, Saint-Germain-enLaye, France) according to manufacturer's recommendations. Briefly, target genes were cloned into the pShuttle vector, sub-cloned into the Adeno-X viral DNA and used to transfect HEK 293 cells with Fugene HD reagent (Roche Applied Science, Basel, Switzerland). After 1 week, viral particles were collected from transfected cells by repeated freezing-thawing and used for re-infection of fresh HEK 293. After 4-5 lysis and infection cycles, viral particles were collected and purified by a double cesium chloride gradient. Viral titer was determined as infectious units after serial infection of HEK 293 cells at different multiplicities of infection, as previously described [21]. Adenoviral vectors were diluted in physiological solution and $20 \mu \mathrm{l}$ were injected in Tibialis Anterior muscles of SCID mice at the titer of $5 \times 10^{9}$ infectious units $/ \mathrm{ml}$.

\section{Tissue staining}

The entire vascular network of the ear could be visualized after intravascular staining with a biotinylated Lycopersicon esculentum (tomato) lectin (Vector Laboratories, Burlingame, CA, USA) that binds the luminal surface of all blood vessels, as previously described [2]. Briefly, mice were anesthetized, lectin was injected intravenously (100 $\mu \mathrm{l}$ per mouse of lectin resuspended at $1 \mathrm{mg} / \mathrm{ml}$ ) and 4 min later the tissues were fixed by vascular perfusion of $1 \%$ paraformaldehyde and $0.5 \%$ glutaraldehyde in PBS $\mathrm{pH} 7.4$ under $120 \mathrm{~mm} / \mathrm{Hg}$ of pressure. Ears were then removed, bisected in the plane of the cartilage, and stained with X-gal staining buffer $(1 \mathrm{mg} / \mathrm{ml}$ 5-bromo-4-chloro-3indoyl- $\beta$-D-galactoside, $5 \mathrm{mM}$ potassium ferricyanide, $5 \mathrm{mM}$ potassium ferrocyanide, $0.02 \%$ Nonidet P-40, $0.01 \%$ sodium deoxycholate, $1 \mathrm{mM} \mathrm{MgCl}_{2}$ in PBS $\mathrm{pH}$ 7.4). Tissues were stained using avidin-biotin complexdiaminobenzidine histochemistry (Vector Laboratories, Burlingame, CA, USA), dehydrated through an alcohol series, cleared with toluene and whole-mounted on glass slides with Permount embedding medium (Fisher Scientific, Wholen, Switzerland). Vascular morphology was analyzed at 4 days and 7 days after implantation for specific experiments.

For tissue sections, mice were anesthetized and the tissues were fixed by vascular perfusion of $1 \%$ paraformaldehyde in PBS pH 7.4 for $4 \mathrm{~min}$ under $120 \mathrm{~mm} / \mathrm{Hg}$ of pressure. TA and
GC muscles were harvested, embedded in OCT compound (CellPath, Newtown, Powys, UK), frozen in freezing isopentane and cryosectioned. Tissue sections were then stained with X-gal ( $20 \mu \mathrm{m}$ sections) to reveal myoblast engraftment or with $\mathrm{H} \& \mathrm{E}$ (10 $\mu \mathrm{m}$ sections) as described previously [22, 23]. Immunofluorescence staining was performed on $12 \mu \mathrm{m}$ thick frozen sections of muscles tissues, cut along the longitudinal axis and on ear whole mounts. The following primary antibodies and dilutions were used: rat anti-CD31 (clone MEC 13.3, BD Biosciences, Basel, Switzerland) at 1:100; rat anti-endomucin (clone V.7C7, Santa Cruz Biotechnology, Santa Cruz, CA, USA) at 1:100; mouse anti- $\alpha$-SMA (clone 1A4, MP Biomedicals, Basel, Switzerland) at 1:400; rabbit anti-NG2 (Chemicon International, Hampshire, UK) at 1:200; chicken anti-laminin (Abcam, Cambridge, UK) at 1:100; rabbit anti-Ki67 (Abcam, Cambridge, UK) at 1:100. Fluorescently labeled secondary antibodies (Invitrogen, Basel, Switzerland) were used at 1:200. Fluorescence images were taken with $40 \times$ or $63 \times$ objectives on a Carl Zeiss LSM710 3-laser scanning confocal microscope (Carl Zeiss, Feldbach, Switzerland). All image analyses were performed with LSM software Zen 2010 (Carl Zeiss, Feldbach, Switzerland).

Vessel analyses

Vessel diameters were measured in whole mounts of ears stained with intravascular L. esculentum lectin perfusion as described [2]. Briefly, vessel diameters were measured by overlaying captured microscopic images with a square grid. Squares were randomly chosen, and the diameter of each vessel (if any) in the center of selected squares was measured. To avoid selection bias, we systematically measured the shortest diameter in the selected vascular segment. About 200 total vessel diameter measurements were obtained from 3 to 5 fields (field size $=575^{\prime} 313 \mu \mathrm{m}^{2}$ ) from each of 6 analyzed ears per group $(n=6)$. All images were taken with a $10 \times$ objective on an Olympus BX61 microscope (Olympus, Volketswil, Switzerland) and analyses were performed with AnalySIS D software (Soft Imaging System Gmbh, Münster, Germany).

Qualitative analysis of vascular morphology in immunofluorescence images was performed on all vascular structures visible in at least 3 fields/section (field size $=45^{\prime} 114 \mu \mathrm{m}^{2}$ ) with a $40 \times$ objective in at least 5 sections/muscle, cut at $150 \mu \mathrm{m}$ of distance from each other, in 3 muscles/group. Therefore, at least 45 microscopic fields were analyzed per group and time-point.

Ki67+ endothelial cells were quantified from the total amount of endothelial cells (300-800 total endothelial cells were counted per condition and per time-point) in up to 3 vascular enlargements visible in each of 3-5 fields in each area of effect (field size $=45^{\prime} 114 \mu \mathrm{m}^{2}$ ). At least five areas with a clear angiogenic effect were analyzed per group. 
Vascular casting

Vascular casts were prepared similarly to the previously described technique [24]. Briefly, the vasculature was perfused with a freshly prepared solution of PU4ii polymer (vasQtec, Zurich, Switzerland). One hour after perfusion, the samples were transferred to $7.5 \%$ potassium hydroxide for dissolution of tissue, which was completed over 2-3 weeks. After washing, the casts were freeze-dried and glued onto the aluminum sample stabs. The samples were then sputtered with gold to a thickness of $10 \mathrm{~nm}$ and examined in a Philips XL-30 SFEG scanning electron microscope. Vascular enlargements were analyzed at least in 5 fields per area of angiogenic effect in 3-4 leg muscles (TA and GC) per group per time-point. TA received 1 cell injection whereas GC received 2 cell implantations (in both the medialis and lateralis portions). Quantification of the numerical pillar density per microvessel area was performed as previously described [25, 26]. Briefly, the total number of pillars was counted per $\mathrm{mm}^{2}$ of vessel area (at least 5 randomly chosen fields of vision (field size $=$ $17^{\prime} 549 \mu \mathrm{m}^{2}$ ) within an area of effect were evaluated; $\geq 5$ areas of effect in each muscle, $\mathrm{n}=2$ muscles). Holes which were representative of pillars with diameter less than $1 \mu \mathrm{m}$ or more than $10 \mu \mathrm{m}$ were not considered.

\section{Semi-thin serial sectioning}

For the preparation of semi-thin sections of the implanted muscles, mice were sacrificed by trans-cardiac intravascular perfusion with a fixative solution composed of $2.5 \%$ (v/v) glutaraldehyde buffered in $0.03 \mathrm{M}$ potassium phosphate ( $\mathrm{pH} \mathrm{7.4,} 370 \mathrm{mOsm}$ ), under physiological pressure of $120 \mathrm{~mm} / \mathrm{Hg}$. The samples were then harvested and left overnight in the same solution. They were then post-fixed in $1 \%$ OsO4 buffered with $0.1 \mathrm{M}$ sodium cacodylate $(\mathrm{pH}$ 7.4, $340 \mathrm{mOsm}$ ), dehydrated in ethanol, and embedded in epoxy resin (Sigma-Aldrich Co., St. Louis, MO, USA). One- $\mu \mathrm{m}$-thick serial sections were prepared using glass knives and stained with Toluidine Blue (Sigma-Aldrich Co., St. Louis, MO, USA). The serial sections were viewed with a Leica DMRB light microscope (Leica microsystems, Heerbrugg, Switzerland) and the images of implantation sites were captured with a $40 \times$ objective using a SIS ColorView 3U Camera (Olympus Europe Holding $\mathrm{GmbH}$, Hamburg, Germany). The set of images obtained was aligned using Photoshop CS3 software (Adobe Systems, San Jose, CA, USA) and imported as a stack into Imaris Software (Bitplane, Zürich, Switzerland) for 3D-reconstruction and image analysis. Vascular enlargements were analyzed in 3-5 fields (field size $=90^{\prime} 220{\mu \mathrm{m}^{2}}^{2}$ ) per area of effect. At least 5 areas were evaluated per muscle $(n=3$ muscles per group per time-point, both TA and GC). TA received 1 cell injection whereas GC received 2 cell implantations (in both the medialis and lateralis portions).

Total RNA and genomic DNA co-isolation and quantitative real-time PCR

Whole fresh mouse muscles were disrupted using a Qiagen Tissue Lyser (Qiagen, Hombrechtikon, Switzerland) to extract total RNA and genomic DNA with a DNA/RNA Mini kit (Qiagen, Hombrechtikon, Switzerland), according to the manufacturer's instructions ( $\mathrm{n}=4$ muscles (both TA and GC) per group and per time-point). Total RNA was reversetranscribed into cDNA with the Omniscript Reverse Transcription kit (Qiagen, Hombrechtikon, Switzerland) at $37{ }^{\circ} \mathrm{C}$ for $60 \mathrm{~min}$. Quantitative Real-Time PCR (qRT-PCR) was performed on an ABI 7300 Real-Time PCR system (Applied Biosystems, Zug, Switzerland). To determine the expression of the genes of interest the following TaqMan gene expression assays (Applied Biosystems, Zug, Switzerland) were used: Nos3 (Mm00435217_m1), Klf2 (Mm01244979_g1) and Gapdh housekeeping gene (Mm03302249_g1). The cycling parameters were: $50{ }^{\circ} \mathrm{C}$ for $2 \mathrm{~min}$, followed by $95^{\circ} \mathrm{C}$ for $10 \mathrm{~min}$ and 40 cycles of denaturation at $95^{\circ} \mathrm{C}$ for $15 \mathrm{~s}$ and annealing/extension at $60^{\circ} \mathrm{C}$ for $1 \mathrm{~min}$. Reactions were performed in triplicate for each template, averaged, and normalized to expression of the Gapdh housekeeping gene.

Statistical analysis

Data are presented as mean \pm standard error. The significance of differences was evaluated using analysis of variance (ANOVA) followed by the Bonferroni test (for multiple comparisons), or using a Student's $t$ test (for single comparisons). $P<0.05$ was considered statistically significant.

\section{Results}

VEGF over-expression induces both normal and aberrant angiogenesis through initial vascular enlargement

We investigated the initial vascular response to different doses of murine $\mathrm{VEGF}_{164}$ in non-ischemic muscle of SCID mice, to avoid the confounding effects of endogenous factor up-regulation and inflammation that occur in ischemic tissue. To address this point, we took advantage of a well-characterized pool of monoclonal populations of retrovirally transduced mouse myoblast. Briefly, primary mouse myoblasts, which already expressed LacZ from a different retroviral construct [22] were transduced with a bicistronic retroviral vector expressing mouse $\mathrm{VEGF}_{164}$ linked to a truncated version of mouse CD8 that acted as a 
convenient cell-surface reporter gene as previously described [18]. Based on the VEGF secretion rates determined by ELISA, we selected 2 clones expressing specific low and high $\mathrm{VEGF}_{164}$ doses $\left(\mathrm{V}_{\text {Low }}=61.0 \pm 2.9\right.$ and $\mathrm{V}_{\text {High }}=121.0 \pm 14.6 \mathrm{ng} / 10^{6}$ cells/day), previously shown to induce normal and therapeutic angiogenesis, or aberrant angioma growth, respectively $[2,3,18]$. It should be noted that both populations, even the $\mathrm{V}_{\text {Low }}$, were previously shown to lead to significantly higher VEGF levels in implanted muscles than those achievable by up-regulation of the endogenous promoter after ischemia [3]: these doses were selected because lower levels of expression were previously shown to be insufficient to bring therapeutic benefit [3]. After implantation, a large proportion of myoblasts dies and up to $10 \%$ stably engraft [27]. We therefore verified the level of exogenous VEGF expression in vivo normalized by the number of surviving cells at each time-point by qRTPCR. As expected in view of the known methylation and partial silencing of the retroviral LTR promoter [28], we found that VEGF expression per cell decreased in both $\mathrm{V}_{\text {Low }}$ and $\mathrm{V}_{\text {High }}$ populations (by about 60 and $20 \%$, respectively) between day 0 and day 7 after implantation in TA muscles (data not shown).

Myoblasts transduced to express mouse CD8 but no VEGF were used as control. Myoblast clonal populations were implanted into the posterior auricular muscle of SCID mice, as the ear microenvironment is thin and particularly advantageous for visualization of the entire vascular architecture and into the Tibialis Anterior (TA) and Gastrocnemius Lateralis (GC) muscles in the hind limb, as the target of therapeutic approaches are the leg muscles. Control myoblasts did not alter the pre-existing vasculature at any time point and were surrounded by morphologically normal capillaries (Fig. 1a, e), covered with pericytes positive for nerve/glial antigen 2 (NG2) (Figs. 2a, d, 3a, d). Four days after myoblast implantation, both clones induced a marked enlargement of the pre-existing vessels (Figs. 1b-c, 2b-c, 3b-c) compared with controls.

Quantification of vessel diameter distribution showed that the degree of vascular enlargements was proportional to VEGF dose. As shown in Fig. 1d, vessels in areas implanted with control CD8 cells were uniformly distributed around a median of $12.5 \mu \mathrm{m}$. $\mathrm{V}_{\text {Low }}$ cells induced heterogeneous vascular enlargements with a median of $20.4 \mu \mathrm{m}$ and 90th percentile of $36.3 \mu \mathrm{m}$, while $\mathrm{V}_{\mathrm{High}}$ cells induced a significantly greater degree of vascular enlargement, with a median of $33.5 \mu \mathrm{m}$ and a 90th percentile of $53.9 \mu \mathrm{m}$ (average diameters: $\quad$ ctrl $=13.0 \pm 0.4 \mu \mathrm{m}, \quad V_{\text {Low }}=23.5 \pm 0.9 \mu \mathrm{m}$ and $\mathrm{V}_{\mathrm{High}}=35.1 \pm 1.0 \mu \mathrm{m} ; P<0.0001$ for all the comparison).

However, by 7 days enlarged vessels remodeled differently depending on VEGF dose, generating either normal capillary networks (Fig. 1f, $\mathrm{V}_{\text {Low }}$ ), which showed well-attached NG2positive pericytes (Figs. 2e, 3e), or aberrant angioma-like structures (Fig. 1g, $\mathrm{V}_{\mathrm{High}}$ ), which lacked NG2-positive pericytes and were coated instead by a thick $\alpha$-SMA-positive smooth muscle layer (Figs. 2f, 3f). At 4 days, enlarged vessels retained NG2-positive pericytes in the presence of low VEGF (Figs. 2b, 3b), whereas many vascular stretches were devoid of mural cells with high VEGF (Figs. 2c, 3c). Careful analysis of the enlarged vessel walls did not reveal any evidence of ab-luminal sprouting, such as filopodia-bearing endothelial tip cells, whereas intravascular protrusions were visible in all enlarged structures at 4 days, suggestive of vascular splitting, or intussusception (Figs. 2g-h, 3g-h). Since filopodia are not optimally marked by CD31 expression, we also used a combination of antibodies against endomucin, which homogeneously stains all endothelial cells, including the filopodia on sprouting tip cells, and laminin, which labels the basal lamina and defines the external boundary of vessels. As shown in Supplemental Fig. 1, at 4 days the endomucin-positive cells of enlarged vascular structures were completely contained within the respective basal lamina and no endothelial extensions could be seen protruding outside of it, thereby confirming the lack of signs of sprouting.

In order to verify whether VEGF diffusion and possible gradient formation may give rise to endothelial sprouting at a distance from the VEGF source, we specifically analyzed vascular morphology at the borders of the myoblast implantation areas at the 4 day time-point. However, the angiogenic effect did not extend beyond the area of the implanted myoblasts, exhibiting a sharp boundary within a few microns of it, in agreement with our own previous results with the same system [2, 29]. Such effect was comprised of circumferential vascular enlargement and transluminal pillar formation also on the edges of such areas, similarly to the results described for the center of the implantation sites (Supplemental Fig. 2).

Furthermore, we asked whether 4 days may be a too long time-point and sprouting may be occurring earlier after VEGF expression. However, 2 days after myoblast implantation vessels next to the injected myoblasts did not yet show signs of either ab-luminal sprouting or circumferential enlargement (Supplemental Fig. 3), suggesting that the enlargements that were evident by 4 days were the first event induced by VEGF over-expression in these conditions and also that they took place quite rapidly, between days 2 and 4 .

Vascular enlargements undergo intussusceptive angiogenesis

Characteristic for the process of intussusception is the formation of transluminal tissue pillars, which fuse progressively together and split the affected vascular segment longitudinally [11]. We addressed whether intussusception 


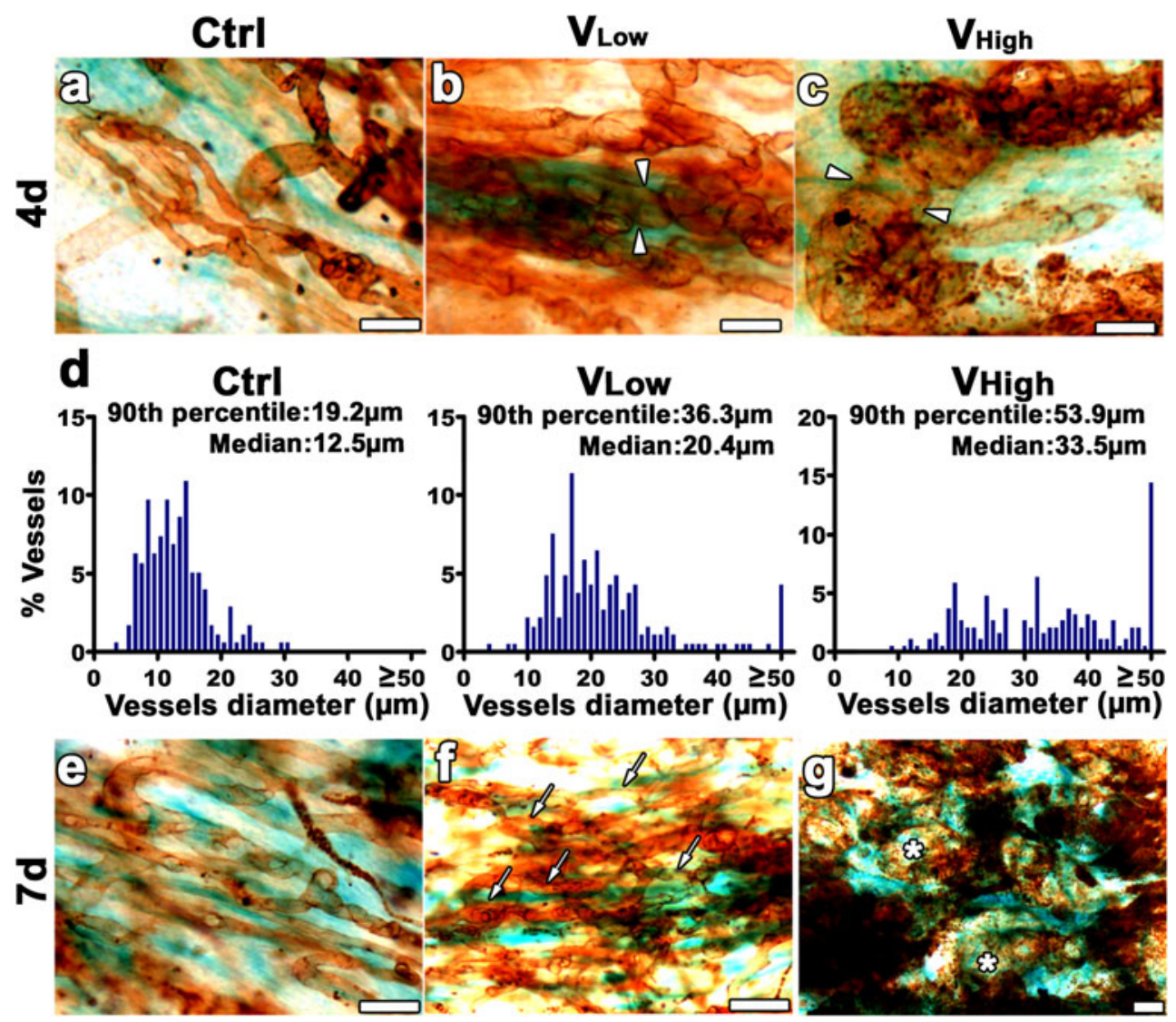

Fig. 1 Vascular morphology 4 and 7 days after over-expression of different VEGF doses. Two clonal populations of transduced myoblasts expressing either a low or a high VEGF dose $\left(\mathrm{V}_{\text {low }}\right.$ and $\mathrm{V}_{\text {high }}$, respectively), and control myoblasts expressing only CD8 (ctrl) were injected in the posterior auricularis muscle. The angiogenic response was analyzed in tissue whole-mounts by lectin staining (brown) and myoblast engraftment was tracked by X-Gal staining (blue-green). a-c Vascular morphology 4 days after cell

was occurring by the gold-standard analysis of vascular corrosion casts [30]. $\mathrm{V}_{\text {Low }}$ and $\mathrm{V}_{\text {High }}$ myoblast clones and control cells were implanted into tibialis anterior and gastrocnemius muscles of SCID mice. Four and seven days later the entire vasculature was cast by perfusion of polyurethane resin and the detailed microvascular morphology was observed by scanning electron microscopy. Control myoblasts did not perturb the pre-existing vasculature at any time-point (Fig. 4a-b, g-h). At 4 days, enlarged vessels induced by both VEGF doses displayed numerous tiny holes that pierced through the vessel casts (Fig. 4c-f), caused by the initial formation of transluminal pillars. By 7 days, vascular casts showed evidence of segregation of new capillary segments by intraluminal pillar fusion in the presence of low VEGF (Fig. $4 \mathrm{i}-\mathrm{j}$ ). In contrast, the aberrant bulbous angioma-like structures induced by high VEGF no longer showed any signs of intraluminal pillar formation (Fig. $4 \mathrm{k}-1$ ). The occurrence of intussusceptive angiogenesis was quantified at 4 days by measuring the numerical density of pillars, defined as the total implantation. Arrowheads indicate the diameters of markedly enlarged vessels at the sites of VEGF over-expression. d The distribution of vessel diameters was quantified in areas implanted with each cell population. e-g By 7 days, control myoblasts did not alter the pre-existing vasculature, whereas enlarged vessels remodeled into morphologically normal capillaries (arrows, $\mathrm{V}_{\text {Low }}$ ) or aberrant angioma-like structures (stars, $\mathrm{V}_{\mathrm{High}}$ ). $\mathrm{n}=6$ ears per group, per timepoint; size bars $=50 \mu \mathrm{m}$. (Color figure online)

number of pillars per $\mathrm{mm}^{2}$ of vascular surface area. As show in Fig. $4 \mathrm{~m}$, the results confirmed the absence of intussusceptive events in control tissues and showed abundant pillar formation in both $\mathrm{V}_{\text {Low }}$ and $\mathrm{V}_{\text {High }}$ conditions $\left(\mathrm{V}_{\text {Low }}=269.6 \pm 43.5\right.$ and $\mathrm{V}_{\text {High }}=542.4 \pm 138.1 ;{ }^{*} P<$ 0.01 and ${ }^{* *} P<0.001$ vs control, respectively). To determine the morphological substrate of the holes observed in the vascular casts, 3D reconstruction of vascular structures was performed from serial semi-thin sections of both TA and GC muscles. Neither vascular cast analysis nor $3 \mathrm{D}$ reconstruction of semi-thin sections are capable of positively identifying sprouting tip cells, but they are ideal to show the presence and structure of intraluminal processes. This analysis confirmed that the visible holes represented transluminal pillars (Fig. 5). At 4 days, enlarged vessels displayed the presence of both intraluminal protrusions made exclusively of endothelial cells and mature, matrix-filled complete pillars, indicated by arrowheads and arrows, respectively, in Fig. 5a-f. By 7 days, fusion of adjacent pillars led to splitting into regular capillary 

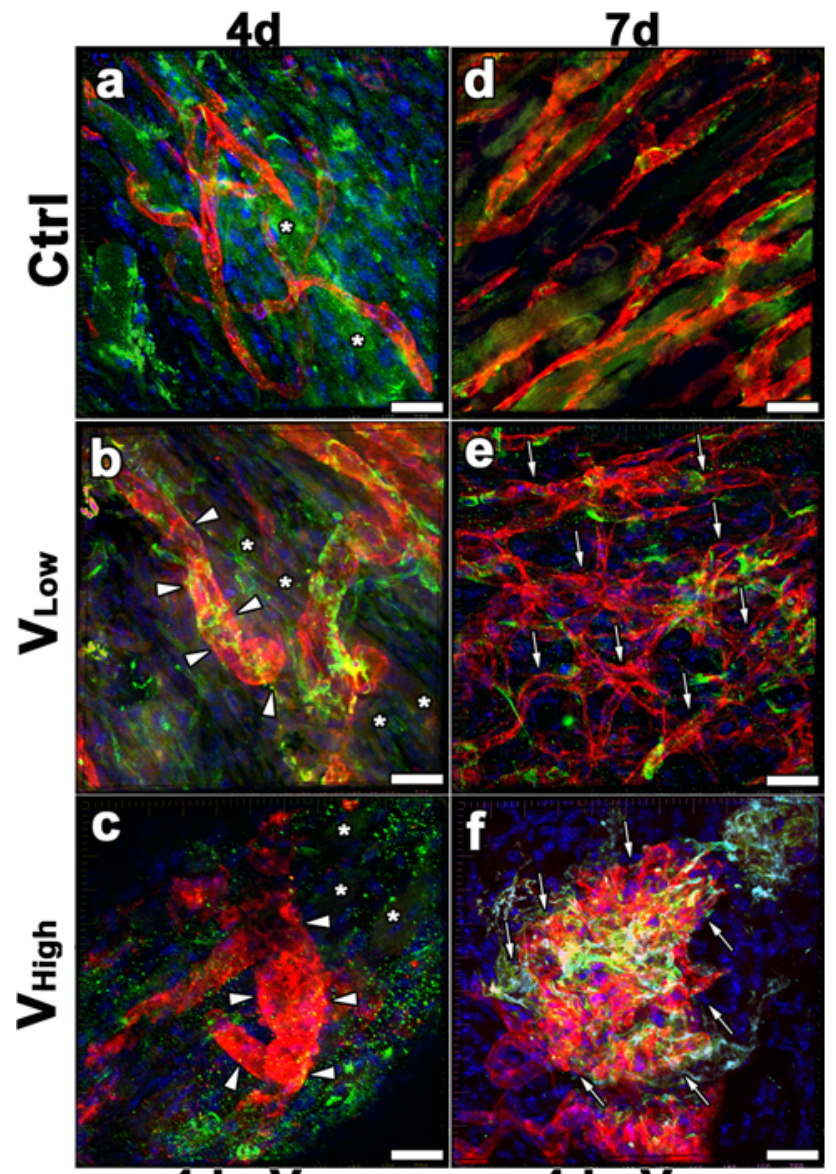

4d - VLow

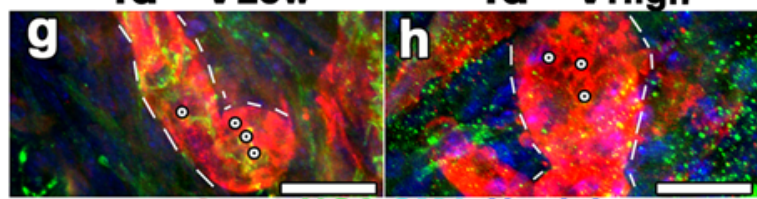

CD31-NG2-SMA-Nuclei

Fig. 2 Mural cell coverage and endothelial morphology during vascular remodeling in ear muscle. Control cells, $\mathrm{V}_{\text {Low }}$ and $\mathrm{V}_{\text {High }}$ myoblast clones were implanted in the posterior auricularis muscle and the induced angiogenesis was analyzed 4 and 7 days later. Whole-mount immunostaining of blood vessels was performed with antibodies against CD31 (endothelial cells, red), NG2 (pericytes, green), $\alpha$-SMA (smooth muscle cells, cyan) and with DAPI (nuclei, blue). a-c By 4 days, VEGF caused vascular enlargements (arrowheads) which were associated with normal $\mathrm{NG} 2+$ pericytes $\left(\mathrm{V}_{\text {Low }}\right)$ or were mainly devoid of mural cell $\left(\mathrm{V}_{\mathrm{High}}\right)$, depending on VEGF dose. d-f By 7 days, vascular enlargements remodeled in networks of morphologically normal and mature capillaries, as shown by the NG2+ pericyte coverage (arrows, $\mathrm{V}_{\text {Low }}$ ) or into aberrant angioma-like structures, which lacked pericytes and were covered with a thick smooth muscle coat (arrows, $\mathrm{V}_{\mathrm{High}}$ ). White asterisks mark the implanted myoblasts. g-h At 4 days enlarged vessels (outlined by dashed lines) showed no evidence of sprout formation and were pierced by numerous trans-luminal holes at both VEGF doses (white dots). $\mathrm{n}=2$ ears per group, per time-point; size bars $=30 \mu \mathrm{m}$. (Color figure online)

segments with low VEGF (Fig. 5g-i), whereas aberrant structures induced by high VEGF displayed only rare fully mature pillars separating large vascular lacunae (Fig. 5j-1).

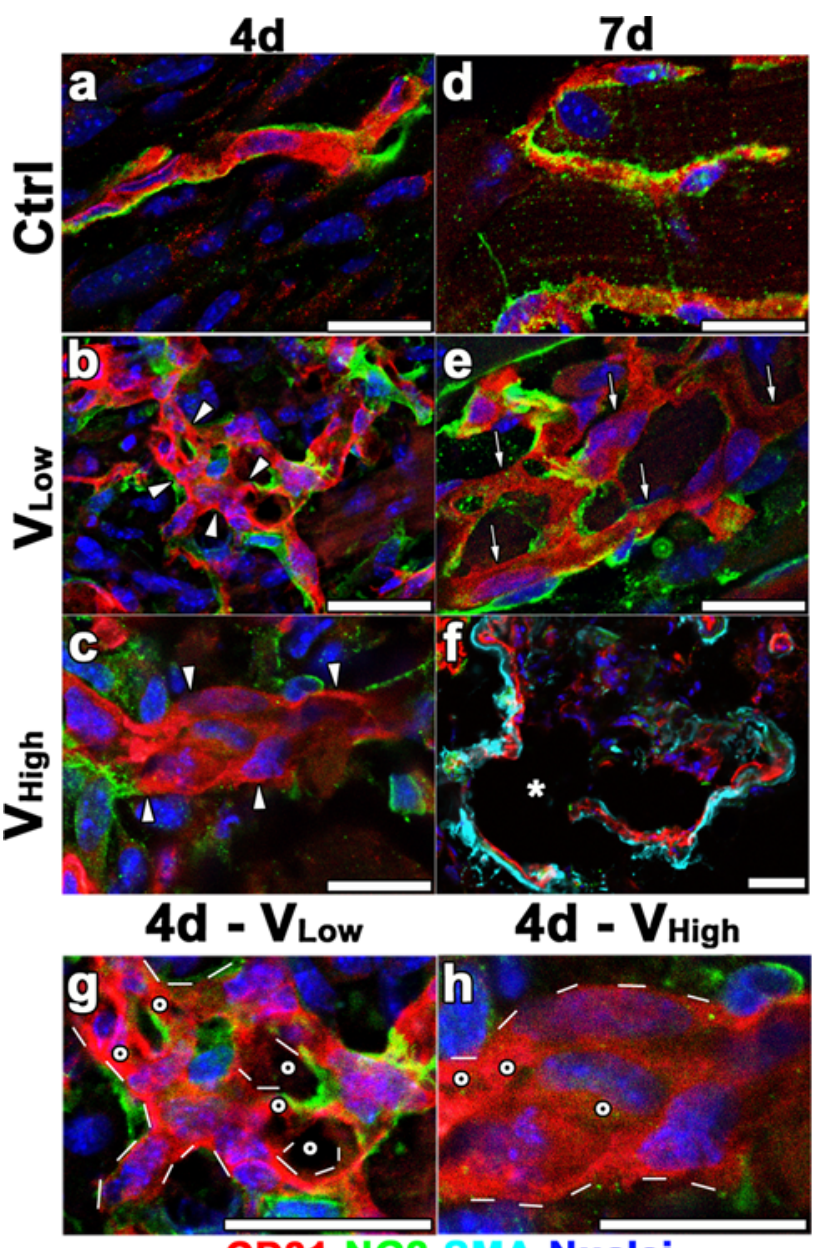

CD31-NG2-SMA-Nuclei

Fig. 3 Mural cell coverage and endothelial morphology during vascular remodeling in limb muscles. Vessels induced by implantation of $\mathrm{V}_{\text {Low }}$ and $\mathrm{V}_{\text {High }}$ myoblast clones were immunostained with antibodies against CD31 (endothelial cells, red), NG2 (pericytes, green), $\alpha$-SMA (smooth muscle cells, cyan) and with DAPI (nuclei, blue) in cryosections of implanted TA and GC muscles. a-c By 4 days, VEGF caused vascular enlargements (arrowheads) which were associated with normal $\mathrm{NG} 2+$ pericytes $\left(\mathrm{V}_{\text {Low }}\right)$ or were mainly devoid of mural cell $\left(\mathrm{V}_{\mathrm{High}}\right)$, depending on VEGF dose. d-f By 7 days, these vascular enlargements remodeled in networks of mature capillaries, as shown by the NG2+ pericyte coverage (arrows, $\mathrm{V}_{\text {Low }}$ ) or into aberrant dilated angioma-like structures, which lacked pericytes and were covered with a thick smooth muscle coat (star, $\mathrm{V}_{\mathrm{High}}$ ). g-h At 4 days enlarged vessels (outlined by dashed lines) showed no evidence of sprout formation and were pierced by numerous trans-luminal holes at both VEGF doses (white dots). $\mathrm{n}=3$ muscles per group, per time-point; size bars $=20 \mu \mathrm{m}$. (Color figure online)

Vascular enlargement is associated with endothelial proliferation and increased blood flow

Vascular enlargement can be due either to expansion of the number of endothelial cells through proliferation or to extension of their surface by thinning and spreading of individual cells, which has been described to occur in the first 

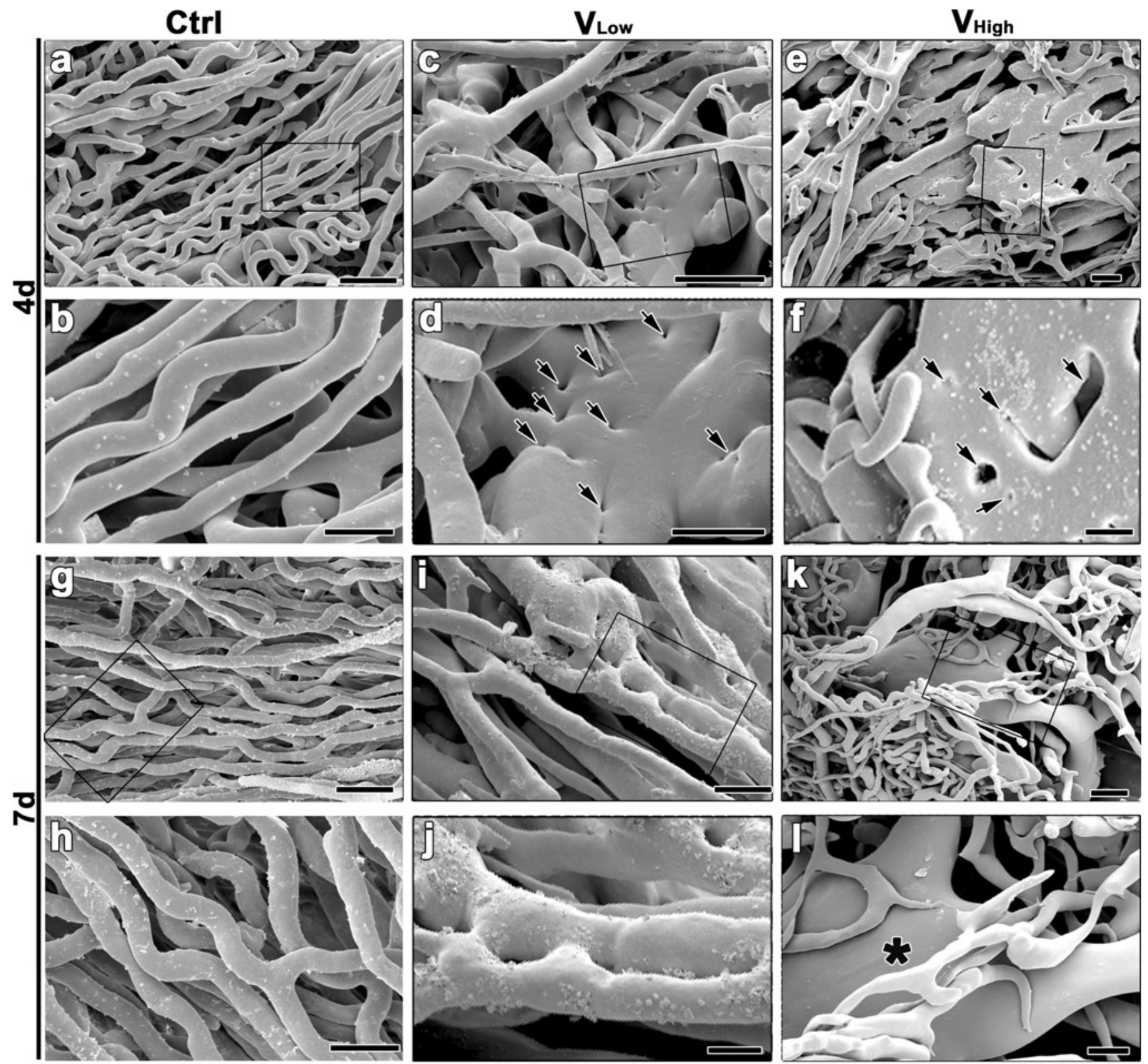

m

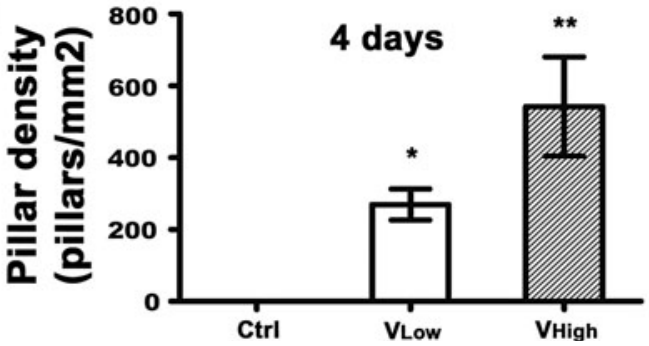

Fig. 4 Scanning electron microscopy analysis of vascular casts. Control cells, $V_{\text {Low }}$ and $V_{\text {High }}$ myoblast clones were implanted in TA and GC muscles of SCID mice and vascular corrosion casts of the entire legs were performed 4 and 7 days post-implantation. a-f At 4 days, enlarged vessels displayed signs of transluminal pillar formation, represented by the numerous small indentations and holes indicated by the black arrows. g-l At 7 days, low VEGF formed normal capillary networks by intussusceptive splitting $\left(\mathrm{V}_{\text {Low }}\right)$, whereas angioma-like structures caused by high VEGF (star, $\mathrm{V}_{\mathrm{High}}$ ) did not show any further signs of pillar formation. $n=3-4$ muscles per group, per time-point. $\mathbf{m}$ Quantification of the numerical pillar density (number of pillars per $\mathrm{mm}^{2}$ of vessel surface area) in vascular casts 4 days after myoblast implantation. ${ }^{*} P<0.01$ and ${ }^{* *} P<0.001 ; \mathrm{n}=2$ muscles per group. Panels $\mathbf{b}, \mathbf{d}, \mathbf{f}, \mathbf{h}, \mathbf{j}$ and $\mathbf{l}$ (size bars $=10 \mu \mathrm{m}$ ) show higher magnification views of the areas indicated by the black squares in panels $\mathbf{a}, \mathbf{c}, \mathbf{e}, \mathbf{g}, \mathbf{i}$ and $\mathbf{k}$, respectively (size bars $=25 \mu \mathrm{m}$ ) 
$24 \mathrm{~h}$ after delivery of a VEGF-expressing adenovirus [31]. Ki67 staining on frozen sections of TA and GC muscles showed that the initial vascular enlargement at 4 days was associated with active endothelial proliferation (Fig. 6a-b). Quantification of the amount of proliferating endothelial nuclei showed no differences between VEGF doses (Fig. 6e, $\mathrm{V}_{\text {Low }}=81.8 \pm 0.7 \%$ and $\mathrm{V}_{\text {High }}=84.8 \pm 1.3 \%$ ). By 7 days, the endothelium of normal capillary networks was almost completely quiescent, whereas that of angioma-like structures continued proliferating (Fig. 6c-e; $\mathrm{V}_{\text {Low }}=7.1 \pm$ $1.3 \%$ and $\left.\mathrm{V}_{\mathrm{High}}=50.1 \pm 2.3 \%,{ }^{* * *} P<0.0001\right)$. Furthermore, Ki67 staining did not reveal any endothelial proliferation 2 days after implantation of either $\mathrm{V}_{\text {Low }}$ or $\mathrm{V}_{\text {High }}$ myoblasts (data not shown).

Quantitative gene expression analysis by qRT-PCR (Fig. 7) showed that the initial vascular enlargement by both VEGF doses was associated with a markedly increased expression of the flow-dependent genes Krüppellike factor-2 (KLF2) and endothelial nitric oxide synthase (eNOS) at 4 days, suggesting that the endothelium of these structures was exposed to increased flow and shear stress. Consistently with the observed vascular morphology, by 7 days expression of both markers remained elevated with high VEGF, but returned to control levels in the presence of low VEGF and normal capillary remodeling.

VEGF over-expression causes intussusceptive angiogenesis also after adenoviral delivery

Lastly, we sought to determine whether VEGF overexpression by an unrelated and clinically relevant gene delivery system would also induce angiogenesis in skeletal

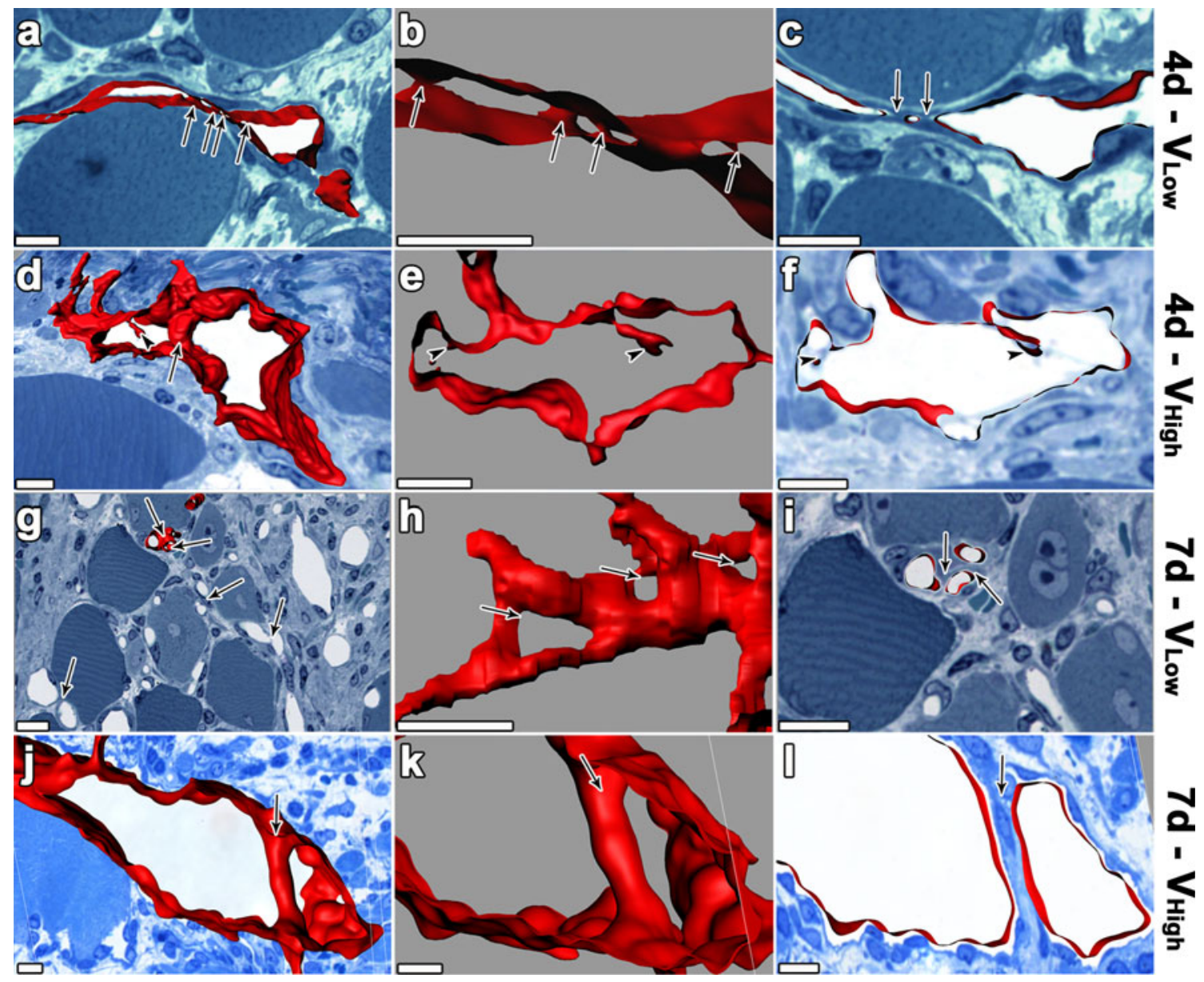

Fig. $53 \mathrm{D}$ reconstructions from serial semi-thin sections. Four and seven days after injection of $\mathrm{V}_{\mathrm{Low}}$ and $\mathrm{V}_{\mathrm{High}}$ clones, hundreds of serial semi-thin sections were obtained from TA and GC muscles and the corresponding 3D stacks were generated from the individual images. a-f At 4 days, reconstructed lumen borders ( $r e d$ ) of enlarged vessels display both mature trans-luminal pillars (arrows) and emerging intraluminal protrusions (arrowheads) built exclusively by endothelial cells. g-l At 7 days, trans-luminal mature pillars (arrows) segregate new normal capillary segments with low VEGF $\left(\mathrm{V}_{\text {Low }}\right)$ and separate large aberrant vascular lacunae with high VEGF $\left(\mathrm{V}_{\mathrm{High}}\right)$. The panels in the left column display overviews of the areas of effect, the panels in the middle column display reconstructed surfaces at a higher magnification from a different perspective, and panels in the right column display a virtual section through the obtained 3D stacks. $\mathrm{n}=3$ muscles per group, per time-point; size bars $=10 \mu \mathrm{m}$. (Color figure online) 


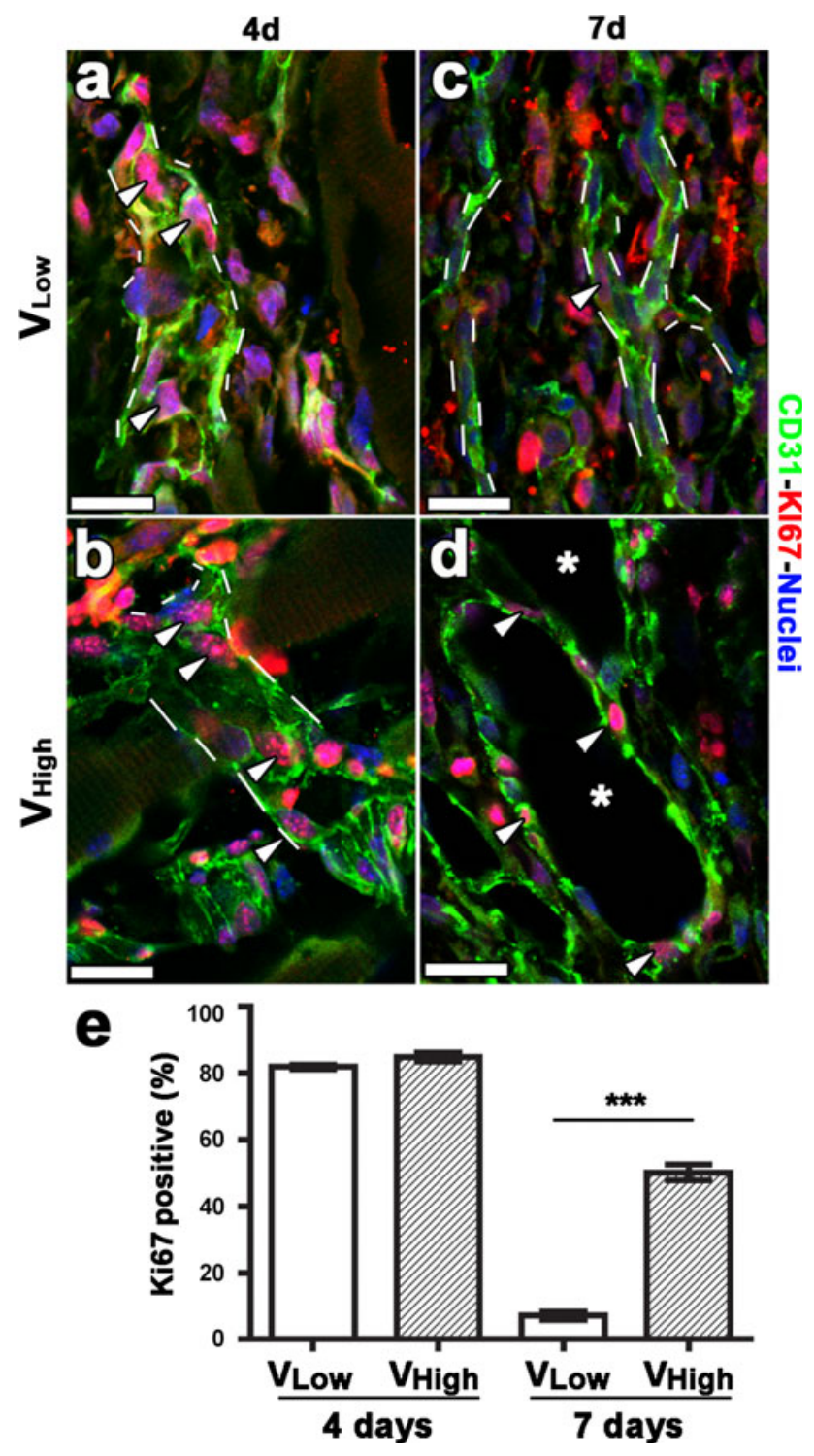

Fig. 6 Vascular enlargement is associated with endothelial proliferation. a-d Immunostaining with antibodies against CD31 (endothelial cells, green), Ki67 (proliferating cells, red) and with DAPI (nuclei, blue) was performed on cryosections of TA and GC muscles 4 and 7 days after myoblast implantation. Vessels are outlined by dashed lines, arrowheads point to proliferating nuclei of endothelial cells and asterisks indicate the lumens of large aberrant angioma-like structures. e The percentage of proliferating endothelial cells was quantified in areas of effect, ${ }^{* * * *} P<0.0001 ; \mathrm{n}=3$ muscles per group, per time-point; size bars $=20 \mu \mathrm{m}$. (Color figure online)

muscle by intussusception rather than sprouting. To test this hypothesis, adenoviral vectors, expressing VEGF $_{164}$ or just a truncated CD8 molecule as control (Ad-VEGF and Ad-CD8) [32], were implanted in TA muscles. Immunostaining of frozen tissue sections and confocal microscopy showed that, while Ad-CD8 did not affect the pre-existing vasculature (Fig. 8a-b), by 4 days Ad-VEGF caused segmental enlargements in existing vessels, without signs of
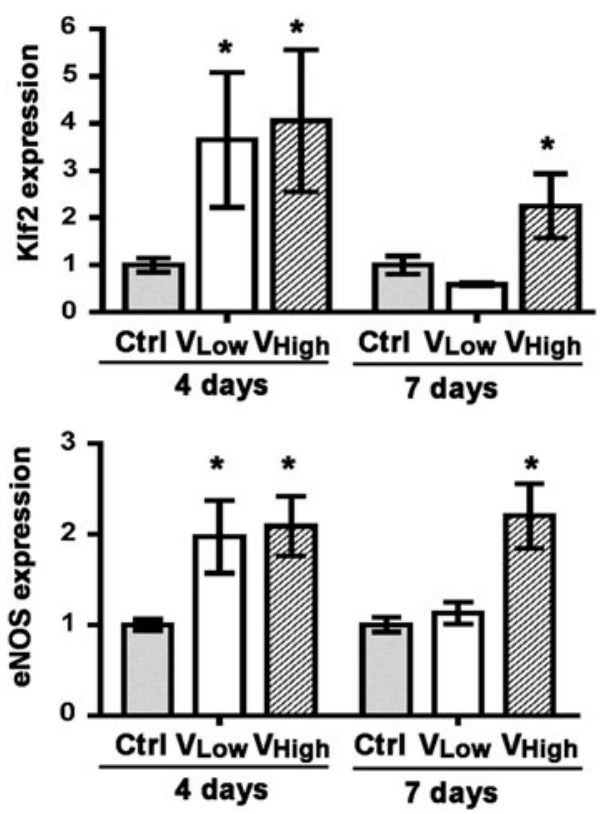

Fig. 7 Vascular enlargement causes increased flow. Total RNA was extracted from TA and GC muscles harvested 4 and 7 days after implantation with control cells $(\mathrm{Ctrl}), \mathrm{V}_{\text {Low }}$ and $\mathrm{V}_{\mathrm{High}}$ myoblast clones. Expression of the flow-dependent genes Klf2 and eNOS was quantified in triplicate by qRT-PCR and normalized to that of the housekeeping gene GAPDH. ${ }^{*} P<0.05$ versus control; $\mathrm{n}=4$ muscles per group, per time-point

sprouting, but with evidence of trans-luminal pillar formation (Fig. 8c). Enlarged vessels subsequently remodeled into angioma-like structures covered by a thick $\alpha$-SMApositive smooth muscle coat (Fig. 8d), similarly to the effects of high-dose VEGF expression by transduced myoblasts. Ki67 staining confirmed that also in this case $>70 \%$ of endothelial cells in the initial vascular enlargements at 4 days were actively proliferating (Fig. 8e-f, AdVEGF $=71.7 \pm 3.4 \%$ ).

\section{Discussion}

By using a highly controlled cell-based gene delivery platform, we could study how angiogenesis is induced by overexpression of specific VEGF doses: one that we have previously shown to be therapeutic and safe in a model of hindlimb ischemia, and one that instead caused angioma growth [3]. Our data from 3 independent and complementary methods (confocal microscopy, vascular casting and 3D reconstruction of serial semi-thin sections) show that in both cases new vascular growth took place essentially without sprouting, but rather by an initial circumferential enlargement of pre-existing vessels and VEGF-induced endothelial proliferation. This in turn was associated with increased flow and shear stress, as evidenced by the up-regulation of the 


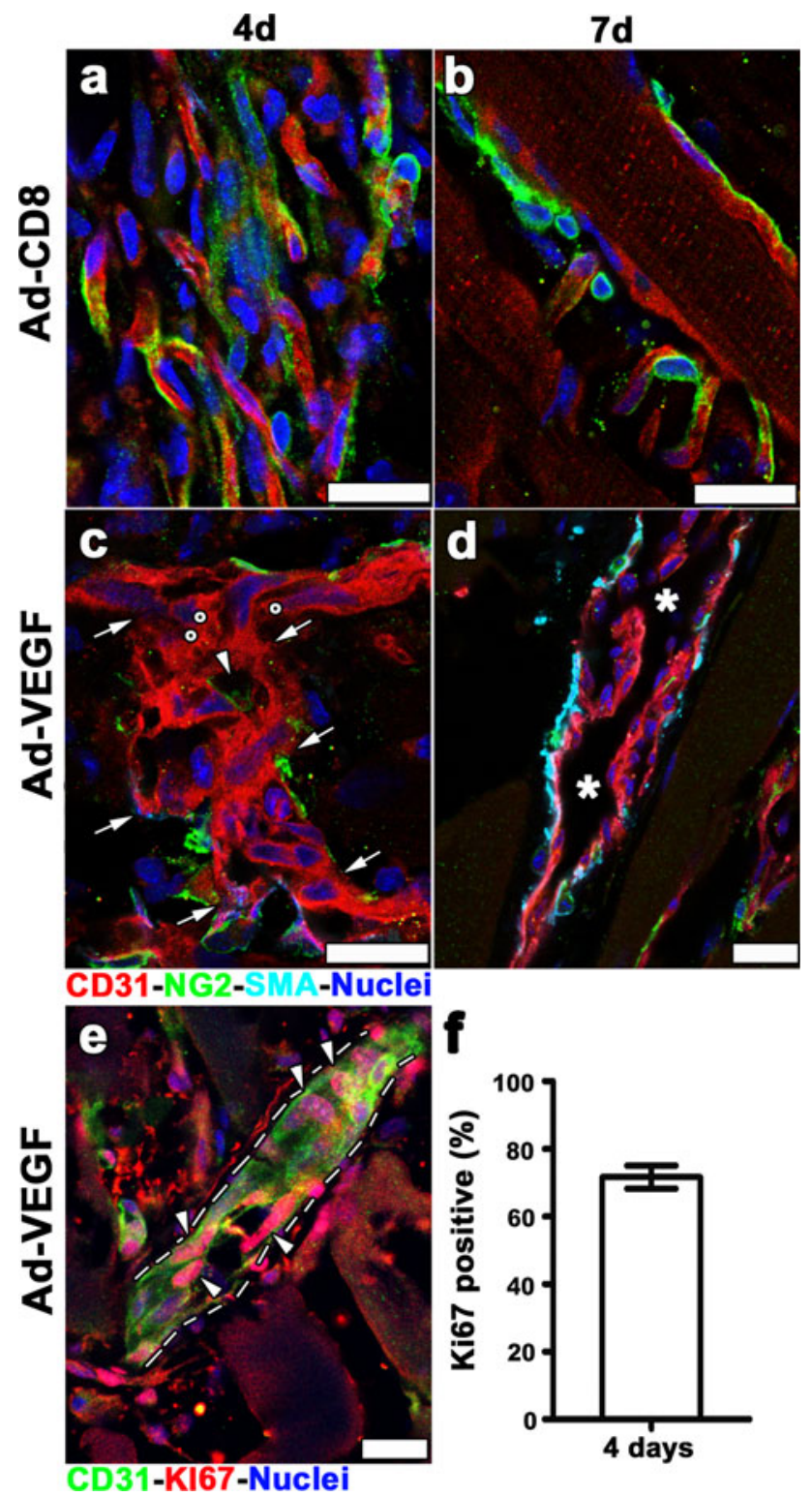

Fig. 8 VEGF adenoviral delivery causes endothelial proliferation and vascular enlargements that remodel by intussusception. a-d Vascular morphology was analyzed 4 and 7 days after injection in TA muscles of adenoviruses expressing VEGF (Ad-VEGF) or only CD8 as control (AdCD8) by immuno-fluorescent staining for CD31 (endothelial cells, red), NG2 (pericytes, green), $\alpha$-SMA (smooth muscle cells, cyan) and DAPI (nuclei, blue) on cryosections. Control Ad-CD8 did not affect normal capillaries lining muscle fibers at either time-point $(\mathbf{a}, \mathbf{b})$. Ad-VEGF caused vascular enlargement (arrows in c), with no signs of extraluminal sprouts and showing evidence of trans-luminal pillar formation, both incipient (white dots in $\mathbf{c}$ ) and more mature, with the presence of a pericyte (arrowhead in c). These enlargements remodeled into angiomalike structures by 7 days (asterisks in $\mathbf{d}$ ). $\mathrm{n}=3$ muscles per group, per time-point; size bars $=20 \mu \mathrm{m}$. e Immunofluorescence staining with antibodies against CD31 (endothelial cells, green), Ki67 (proliferating cells, red) and DAPI (nuclei, blue) on cryosections of TA muscles 4 days after Ad-VEGF injection. A vascular enlargement is outlined by dashed lines, while arrowheads point to the nuclei of proliferating endothelial cells. $\mathbf{f}$ The percentage of proliferating endothelial cells was quantified in areas of effect. $\mathrm{n}=2$ muscles; size bars $=20 \mu \mathrm{m}$. (Color figure online) transcription factor Klf2, that mediates endothelial responses to shear stress [33, 34]. These hemodynamic stimuli are potent triggers for intussusception [16]. In fact, acute increases in flow and shear stress in microvascular networks have been found to rapidly initiate pillar formation and capillary splitting even without endothelial proliferation or growth factor delivery $[12,35]$. We have previously shown that clamping of arterial side-branches in fully mature 16-day-old chicken chorioallantoic membranes led to a greater than $50 \%$ increase in the downstream flow rate and the appearance of transluminal pillars in capillaries as early as $40 \mathrm{~min}$ later [35]. The immediacy of the response indicates that the hemodynamic trigger is sufficient and does not require changes in gene expression to initiate the intussusceptive process. Hudlicka and coworkers further demonstrated that treatment with the $\alpha 1$-adrenergic receptor blocker prazosin, which increases blood flow and shear stress in the downstream microvascular networks purely through arterial vasodilation, induced vascular growth in skeletal muscle by capillary splitting without any proliferation of endothelial cells [12].

Interestingly, our data also suggest that pericytes are not necessary to initiate intussusception. In fact, 4 days after high VEGF expression enlarged vessels were mostly devoid of pericytes, in agreement with the recently described negative regulation of pericytes by VEGF [36], yet pillar formation took place unimpeded and no NG2+ cell could be found in association with the initiating endothelial invaginations (Figs. 2h, 3h).

Since different muscles have different vessel densities depending on whether they are composed prevalently of anaerobic fast-twitch or glycolytic slow-twitch fibers [37], it would be interesting to understand whether VEGF overexpression may have different outcomes depending on the muscle metabolic type. Unfortunately, both the TA and the GC muscles, which we injected, belong to the fast type, although the GC contains a small (3\%) proportion of type 1 slow-twitch fibers in the internal part [37], and therefore our results do not allow an answer to this question, which should be addressed by ad hoc systematic experiments.

During sprouting, specialized endothelial tip cells are formed that sense a VEGF gradient through filopodia extensions and migrate towards it, while stalk cells proliferate behind to form the new vessel lumen [7]. If a VEGF gradient is lacking, e.g. when the non-matrix-binding isoform $\mathrm{VEGF}_{121}$ is expressed, endothelial cells proliferate without migrating and lead to vessel enlargement instead [38]. Our data indicate that over-expression of the matrixbinding $\mathrm{VEGF}_{164}$ at two different supra-physiologic doses induced vascular enlargement with robust endothelial proliferation in the absence of migrating tip cells, followed by transluminal pillar formation and intussusceptive remodeling. Indeed, vascular enlargement per se can induce 
endothelial proliferation [39], but we also have previously found that, in this system, initial vascular enlargement depends on VEGF signaling and regresses completely after treatment with a VEGF-Trap [2]. On the other hand, sprouting has been reported to take place during spontaneous angiogenesis after skeletal muscle ischemia, although an attempt to stimulate this process by systemic inhibition of Dll4/Notch1 signaling did not result in ischemia improvement, but actually led to an increase in dysfunctional angiogenesis [10]. The absence of any sprouting we found is likely due to differences in the VEGF dose achieved in tissue. In fact, as VEGF accumulates in the limited amount of extracellular matrix between muscle fibers, it can saturate the microenvironment and abolish the formation of a gradient capable of inducing tip cell migration. Indeed, we previously found that 3 days after induction of hind-limb ischemia the levels of endogenous VEGF moderately increased about 3 -fold, whereas treatment with the low VEGF-expressing myoblast clone used here, that was both therapeutic and safe in the same experiments, led to an 18 -fold increase in muscle VEGF concentration [3]. Taken together, these results suggest that VEGF doses higher than the maximal up-regulation achieved by the endogenous response are necessary for therapeutic benefit, but induce angiogenesis by a different mechanism. In agreement with our findings, a recent doseescalation study of adenoviral VEGF delivery to rabbit skeletal muscle showed that sprouting occurred with low VEGF and capillary enlargement with higher doses, but functional benefits were seen only with enlarged vessels [40]. In that study, the mechanisms of new vessel formation after initial enlargement could not be investigated due to the shortterm duration of adenoviral expression in immunocompetent animals, but the complete switch from sprouting to vessel enlargement, as well as the maximal perfusion improvement, occurred with adenoviral titers from $10^{10}$ particles $/ \mathrm{ml}$, corresponding to about $5 \times 10^{8}$ infectious units $/ \mathrm{ml}$, and higher [40]. This is in good agreement with our results reported here that show absence of sprouting with an adenoviral titer of $5 \times 10^{9}$ infectious units $/ \mathrm{ml}$.

On the basis of our results, it is possible to speculate on how the same process of intussusception may result in either normal or aberrant angiogenesis depending on the VEGF dose. In fact, the density of pillars that form per unit of vascular surface area at 4 days is not statistically different between low and high VEGF doses (Fig. 4m). However, the high VEGF dose caused vessels to enlarge significantly more at this stage than the low VEGF dose, with more than $50 \%$ of the structures having a diameter $>30 \mu \mathrm{m}$ (Fig. 1d). It is therefore plausible that, while pillar formation is initiated in both cases by the increased shear stress that follows enlargement, mature pillars may fail to complete in the presence of an excessive diameter to bridge, causing the affected vascular segments to continue growing into angioma-like structures. On the other hand, the successful completion of intussusceptive remodeling in smaller-caliber vascular enlargements would generate the normal capillary networks observed with low VEGF. Highresolution time-lapse in vivo imaging experiments will be required to validate this hypothesis.

From a functional point of view, simulations with a computational model have shown that vascular networks induced by intussusception and by sprouting are similarly effective under steady-state conditions of moderate oxygen consumption [41]. However, the same computational model also found that intussusceptive networks become more effective in oxygen delivery under conditions of high metabolic demand. Furthermore, intussusception has the potential to provide more rapid functional relief in conditions of ischemia. In fact, the very initial stage of intussusception, i.e. vascular enlargement, ensures an immediate increase in flow in the affected region, whereas sprouts are not functional until fusion with another sprout allows effective flow to start in the new vessel [16]. The greater functional efficacy of vascular enlargement compared to sprouting was also shown by the dose-escalation study of adenoviral VEGF delivery to rabbit skeletal muscle described above [40]. The rapid increase in flow and shear stress caused by initial vascular enlargement also triggers intussusceptive remodeling [16], thereby limiting flow in each of the resulting normal-size microvessels to physiological levels and returning the system to the steady-state.

In conclusion, our results show that VEGF overexpression in skeletal muscle, at the doses required to induce functional benefit, induces vascular growth prevalently by intussusception rather than sprouting. Therefore, for the rational design of novel therapeutic angiogenesis approaches, it will be key to elucidate the molecular mechanisms controlling intussusception, which are still poorly understood compared to sprouting due to a paucity of appropriate models. The cell-based platform used in this work for controlled expression of specific VEGF doses in skeletal muscle, based on monoclonal populations of transduced myoblasts, may represent a useful such model to study the mechanisms of intussusceptive angiogenesis in a clinically relevant tissue.

Acknowledgments We are grateful to Werner Graber and Regula Beurgy for valuable technical support. This work was supported by the Swiss National Science Foundation grant 310030_127426 to A.B. and 31003A_135740 to V.D.

Conflict of interest The authors declare that they have no conflict of interest.

Ethical standards The experiments described in this work comply with all applicable laws of Switzerland. 


\section{References}

1. Yla-Herttuala S, Rissanen TT, Vajanto I, Hartikainen J (2007) Vascular endothelial growth factors: biology and current status of clinical applications in cardiovascular medicine. J Am Coll Cardiol 49(10):1015-1026

2. Ozawa CR, Banfi A, Glazer NL, Thurston G, Springer ML, Kraft PE, McDonald DM, Blau HM (2004) Microenvironmental VEGF concentration, not total dose, determines a threshold between normal and aberrant angiogenesis. J Clin Invest 113(4):516-527

3. von Degenfeld G, Banfi A, Springer ML, Wagner RA, Jacobi J, Ozawa CR, Merchant MJ, Cooke JP, Blau HM (2006) Microenvironmental VEGF distribution is critical for stable and functional vessel growth in ischemia. FASEB J 20(14):2657-2659

4. Banfi A, von Degenfeld G, Blau HM (2005) Critical role of microenvironmental factors in angiogenesis. Curr Atheroscler Rep 7(3):227-234

5. Karvinen H, Ylä-Herttuala S (2010) New aspects in vascular gene therapy. Curr Opin Pharmacol 10(2):208-211

6. Yla-Herttuala S, Markkanen JE, Rissanen TT (2004) Gene therapy for ischemic cardiovascular diseases: some lessons learned from the first clinical trials. Trends Cardiovasc Med 14(8): 295-300

7. Gerhardt H, Golding M, Fruttiger M, Ruhrberg C, Lundkvist A, Abramsson A, Jeltsch M, Mitchell C, Alitalo K, Shima D, Betsholtz C (2003) VEGF guides angiogenic sprouting utilizing endothelial tip cell filopodia. J Cell Biol 161(6):1163-1177

8. Brown MD, Hudlicka O (2003) Modulation of physiological angiogenesis in skeletal muscle by mechanical forces: involvement of VEGF and metalloproteinases. Angiogenesis 6(1):1-14

9. Egginton S (2011) Physiological factors influencing capillary growth. Acta Physiol (Oxf) 202(3):225-239

10. Al Haj Zen A, Oikawa A, Bazan-Peregrino M, Meloni M, Emanueli C, Madeddu P (2010) Inhibition of delta-like-4-mediated signaling impairs reparative angiogenesis after ischemia. Circ Res 107(2):283-293

11. Makanya AN, Hlushchuk R, Djonov VG (2009) Intussusceptive angiogenesis and its role in vascular morphogenesis, patterning, and remodeling. Angiogenesis 12(2):113-123

12. Egginton S, Zhou AL, Brown MD, Hudlicka O (2001) Unorthodox angiogenesis in skeletal muscle. Cardiovasc Res 49(3): 634-646

13. Hudlicka O, Brown MD (2009) Adaptation of skeletal muscle microvasculature to increased or decreased blood flow: role of shear stress, nitric oxide and vascular endothelial growth factor. J Vasc Res 46(5):504-512

14. Milkiewicz M, Kelland C, Colgan S, Haas TL (2006) Nitric oxide and p38 MAP kinase mediate shear stress-dependent inhibition of MMP-2 production in microvascular endothelial cells. J Cell Physiol 208(1):229-237

15. Djonov V, Baum O, Burri PH (2003) Vascular remodeling by intussusceptive angiogenesis. Cell Tissue Res 314(1):107-117

16. Styp-Rekowska B, Hlushchuk R, Pries AR, Djonov V (2011) Intussusceptive angiogenesis: pillars against the blood flow. Acta Physiol (Oxf) 202(3):213-223

17. Zhou A, Egginton S, Hudlicka O, Brown MD (1998) Internal division of capillaries in rat skeletal muscle in response to chronic vasodilator treatment with alpha1-antagonist prazosin. Cell Tissue Res 293(2):293-303

18. Misteli H, Wolff T, Fuglistaler P, Gianni-Barrera R, Gurke L, Heberer M, Banfi A (2010) High-throughput flow cytometry purification of transduced progenitors expressing defined levels of vascular endothelial growth factor induces controlled angiogenesis in vivo. Stem Cells 28(3):611-619
19. Springer ML, Blau HM (1997) High efficiency retroviral infection of primary myoblasts. Somat Cell Mol Genet 23:203-209

20. Banfi A, Springer ML, Blau HM (2002) Myoblast-mediated gene transfer for therapeutic angiogenesis. Methods Enzymol 346: $145-157$

21. Gueret V, Negrete-Virgen JA, Lyddiatt A, Al-Rubeai M (2002) Rapid titration of adenoviral infectivity by flow cytometry in batch culture of infected HEK293 cells. Cytotechnology 38(1-3):87-97

22. Rando TA, Blau HM (1994) Primary mouse myoblast purification, characterization, and transplantation for cell-mediated gene therapy. J Cell Biol 125(6):1275-1287

23. Springer ML, Blau HM (1997) High-efficiency retroviral infection of primary myoblasts. Somat Cell Mol Genet 23(3):203-209

24. Hlushchuk R, Ehrbar M, Reichmuth P, Heinimann N, Styp-Rekowska B, Escher R, Baum O, Lienemann P, Makanya A, Keshet E, Djonov V (2011) Decrease in VEGF expression induces intussusceptive vascular pruning. Arterioscler Thromb Vasc Biol 31(12):2836-2844

25. Hlushchuk R, Riesterer O, Baum O, Wood J, Gruber G, Pruschy M, Djonov V (2008) Tumor recovery by angiogenic switch from sprouting to intussusceptive angiogenesis after treatment with PTK787/ZK222584 or ionizing radiation. Am J Pathol 173(4): $1173-1185$

26. Makanya AN, Hlushchuk R, Baum O, Velinov N, Ochs M, Djonov V (2007) Microvascular endowment in the developing chicken embryo lung. Am J Physiol Lung Cell Mol Physiol 292(5):L1136-L1146

27. Gussoni E, Blau HM, Kunkel LM (1997) The fate of individual myoblasts after transplantation into muscles of DMD patients. Nat Med 3(9):970-977

28. Ellis J (2005) Silencing and variegation of gammaretrovirus and lentivirus vectors. Hum Gene Ther 16(11):1241-1246

29. Springer ML, Banfi A, Ye J, von Degenfeld G, Kraft PE, Saini SA, Kapasi NK, Blau HM (2007) Localization of vascular response to VEGF is not dependent on heparin binding. FASEB J 21(9):2074-2085

30. Djonov V, Burri PH (2004) Corrosion cast analysis of blood vessels. In: Augustin $\mathrm{H}$ (ed) Methods in endothelial cell biology. Springer, Berlin

31. Pettersson A, Nagy JA, Brown LF, Sundberg C, Morgan E, Jungles S, Carter R, Krieger JE, Manseau EJ, Harvey VS, Eckelhoefer IA, Feng D, Dvorak AM, Mulligan RC, Dvorak HF (2000) Heterogeneity of the angiogenic response induced in different normal adult tissues by vascular permeability factor/ vascular endothelial growth factor. Lab Invest 80(1):99-115

32. Banfi A, Von Degenfeld G, Gianni-Barrera R, Reginato S, Merchant MJ, McDonald DM, Blau HM (2012) Therapeutic angiogenesis due to balanced single-vector delivery of VEGF and PDGF-BB. FASEB J 26(6):2486-2497

33. Atkins GB, Jain MK (2007) Role of Kruppel-like transcription factors in endothelial biology. Circ Res 100(12):1686-1695

34. Dekker RJ, van Thienen JV, Rohlena J, de Jager SC, Elderkamp YW, Seppen J, de Vries CJ, Biessen EA, van Berkel TJ, Pannekoek H, Horrevoets AJ (2005) Endothelial KLF2 links local arterial shear stress levels to the expression of vascular toneregulating genes. Am J Pathol 167(2):609-618

35. Djonov VG, Kurz H, Burri PH (2002) Optimality in the developing vascular system: branching remodeling by means of intussusception as an efficient adaptation mechanism. Dev Dyn 224(4):391-402

36. Greenberg JI, Shields DJ, Barillas SG, Acevedo LM, Murphy E, Huang J, Scheppke L, Stockmann C, Johnson RS, Angle N, Cheresh DA (2008) A role for VEGF as a negative regulator of pericyte function and vessel maturation. Nature 456(7223):809-813 
37. Schiaffino S, Reggiani C (2011) Fiber types in mammalian skeletal muscles. Physiol Rev 91(4):1447-1531

38. Ruhrberg C, Gerhardt H, Golding M, Watson R, Ioannidou S, Fujisawa H, Betsholtz C, Shima DT (2002) Spatially restricted patterning cues provided by heparin-binding VEGF-A control blood vessel branching morphogenesis. Genes Dev 16(20):2684-2698

39. Milkiewicz M, Brown MD, Egginton S, Hudlicka O (2001) Association between shear stress, angiogenesis, and VEGF in skeletal muscles in vivo. Microcirculation 8(4):229-241
40. Korpisalo P, Hytonen JP, Laitinen JT, Laidinen S, Parviainen H, Karvinen H, Siponen J, Marjomaki V, Vajanto I, Rissanen TT, YlaHerttuala S (2011) Capillary enlargement, not sprouting angiogenesis, determines beneficial therapeutic effects and side effects of angiogenic gene therapy. Eur Heart J 32(13):1664-1672

41. Ji JW, Tsoukias NM, Goldman D, Popel AS (2006) A computational model of oxygen transport in skeletal muscle for sprouting and splitting modes of angiogenesis. J Theor Biol 241(1):94-108 